Article

\title{
Amplitude-Preserved Wave Equation: An Example to Image the Gas Hydrate System
}

\author{
Jiachun You ${ }^{1}$, Sha Song ${ }^{2,3, *}$, Umberta Tinivella ${ }^{3}{ }^{[}$, Michela Giustiniani ${ }^{3} \mathbb{D}$ and Iván Vargas-Cordero ${ }^{3}$ \\ 1 School of Geophysics, Chengdu University of Technology, Chengdu 610059, China; youjiachun@cdut.edu.cn \\ School of Geological Engineering and Geomatics, Chang'an University, Xi'an 710054, China \\ 3 Istituto Nazionale di Oceanografia e di Geofisica Sperimentale (OGS), Borgo Grotta 42C, 34010 Trieste, Italy; \\ utinivella@inogs.it (U.T.); mgiustiniani@inogs.it (M.G.); lacruzvargas@gmail.com (I.V.-C.) \\ * Correspondence: shasong@chd.edu.cn
}

Citation: You, J.; Song, S.; Tinivella,

U.; Giustiniani, M.; Vargas-Cordero, I. Amplitude-Preserved Wave Equation: An Example to Image the Gas Hydrate System. Energies 2021, 14, 3700. https://doi.org/10.3390/ en14123700

Academic Editor: Jacek Majorowicz

Received: 24 May 2021

Accepted: 18 June 2021

Published: 21 June 2021

Publisher's Note: MDPI stays neutral with regard to jurisdictional claims in published maps and institutional affiliations.

Copyright: (c) 2021 by the authors. Licensee MDPI, Basel, Switzerland. This article is an open access article distributed under the terms and conditions of the Creative Commons Attribution (CC BY) license (https:// creativecommons.org/licenses/by/ $4.0 /)$.

\begin{abstract}
Natural gas hydrate is an important energy source. Therefore, it is extremely important to provide a clear imaging profile to determine its distribution for energy exploration. In view of the problems existing in conventional migration methods, e.g., the limited imaging angles, we proposed to utilize an amplitude-preserved one-way wave equation migration based on matrix decomposition to deal with primary and multiple waves. With respect to seismic data gathered at the Chilean continental margin, a conventional processing flow to obtain seismic records with a high signal-tonoise ratio is introduced. Then, the imaging results of the conventional and amplitude-preserved one-way wave equation migration methods based on primary waves are compared, to demonstrate the necessity of implementing amplitude-preserving migration. Moreover, a simple two-layer model is imaged by using primary and multiple waves, which proves the superiority of multiple waves in imaging compared with primary waves and lays the foundation for further application. For the real data, the imaging sections of primary and multiple waves are compared. We found that multiple waves are able to provide a wider imaging illumination while primary waves fail to illuminate, especially for the imaging of bottom simulating reflections (BSRs), because multiple waves have a longer travelling path and carry more information. By imaging the actual seismic data, we can make a conclusion that the imaging result generated by multiple waves can be viewed as a supplementary for the imaging result of primary waves, and it has some guiding values for further hydrate and in general shallow gas exploration.
\end{abstract}

Keywords: depth migration; primary wave imaging; multiple wave imaging; matrix decomposition

\section{Introduction}

Gas hydrates (GHs) are ice-like crystalline solids composed of cages of water molecules that surround low-molecular-weight gas molecules, which form under low-temperature and high-pressure conditions, and when adequate gas concentration is available [1]. Hydrates are widely present in marine sediments both along active and passive continental margins and permafrost environments [2]. The presence of GH in the marine sediments is often inferred by identifying a bottom simulating reflection (BSR) in seismic imaging data [3]. The BSR, which marks the base of the gas hydrate stability zone, represents a strong impedance contrast between high velocity hydrate-bearing sediments above and underlying low velocity free gas-bearing sediments. In the last decades, interest in GHs has been significantly increasing because of their economic potential as a future energy source [4,5] and their potential role in geohazards [6-8] and global climate change [9-15].

Along the Chilean continental margin, BSR has been reported by several geophysical studies, which provide evidence for the occurrence of a potential gas hydrate reservoir (i.e., $[16,17])$. Recent studies pointed out that a GH reservoir present is very interesting from an energy point of view, but also very sensitive to natural phenomena, such as climate 
change, slope stability and earthquakes (i.e., [18]). Therefore, it is very important to increase existing knowledge on GH systems at the Chilean margin, including a good subsoil image.

Achieving a high-quality imaging result is a direction in which researchers have constantly devoted efforts. A clear imaging section of sediments should be helpful to offshore energy exploration such as petroleum or $\mathrm{GH}$, because seismic exploration is the main tool to investigate subsoil energy resources. In general, the elastic wave equation is utilized to describe the wavefield propagation and imaging in seismic exploration. Here, we propose the use of the amplitude-preserved one-way wave equation migration method to image the gas hydrate system. One-way wave equation migration is one of the most widely used seismic migration due to its high efficiency. The one-way wave equations are split from two-way wave equation, and one-way wave equation migration methods have many achievements with decades of development [19]. The core of one-way wave equation migration is how to calculate the vertical wavenumber. The common approach is to use Taylor expansion to approximate it. Based on different orders of Taylor expansion, one-way wave equation migrations can be based on different methods, such as phaseshift (PS) method, split-step Fourier (SSF) method, Fourier finite-difference (FFD) method and generalized screen propagator (GSP) method [20-22]. Owing to the limited Taylor expansion, the conventional one-way wave equation migration methods have a limited imaging angle which, for complicated models, could be a disadvantage.

Some researchers have done a great deal of work in solving one-way true amplitude equations to produce satisfactory imaging results [23,24], for example, the beamlet propagator is combined with it [25]. As mentioned above, based on the achievements of one-way wave equation migration, the theories of approximation, such as Taylor expansion, are used to solve one-way true amplitude equations [26-29]. In order to solve the issue of the limited imaging angle, ref. [30] proposed to apply the matrix decomposition theory to calculate one-way true amplitude equations, which achieves a better imaging result compared with the one-way true amplitude equation migration method based on Taylor expansion. The conventional one-way wave equation can only keep the kinematics of two-way wave equation but fails to provide kinetical characteristics. However, the kinetical characteristics, such as amplitudes, are very important for imaging the subsoil, in particular the GH system, because the inversion of elastic parameters could be performed in order to extract petrophysical properties for energy exploration and/or environmental purposes. Therefore, one-way true amplitude migration theories considering an amplitude-correction term are proposed herein.

In marine seismic exploration, multiple waves are a very common wavefield phenomenon because of the strong reflection coefficient of the sea surface. In the conventional seismic data processing, multiple waves are viewed as noises and should be attenuated, to increase the resolution of seismic data [31]. In fact, multiple waves carry information on the subsurface as well; so, a reasonable usage of multiple waves can produce a positive impact on seismic imaging, as recently demonstrated (i.e., [32]). The theory, proposed by [33], uses the multiple waves as the receiver wavefield, while the primary waves as the source wavefield to perform seismic imaging based on the conventional migration methods. Another method is based on two steps: (1) convert multiple waves into new-defined primary wave; and (2) perform seismic depth migration by following the conventional approaches [34]. By using the above theories, based on the separation of multiple waves, it is very difficult to accurately separate multiple waves in some complex geological settings. In order to avoid the separation of multiple waves, it is possible to jointly perform the imaging of primary and multiple waves; this method was successfully applied in reverse time migration and least squares migration [35]. Recently, researchers developed sophisticated algorithms to use multiple waves to deal with complex imaging tasks. Ref. [36] proposed a viscoacoustic reverse time migration method to image different order multiple waves. Ref. [37] used multiple waves to update a converted velocity result of waveform inversion and improved the accuracy of velocity inversion. Ref. [38] proposed applying multiple waves to compen- 
sate for the missing parts in the case of large acquisition gaps because of various obstacles, such as platforms.

The main aim of our manuscript was employing the matrix decomposition method to implement preserved-amplitude one-way wave equation in imaging GH system and compare imaging differences by using primary and multiple waves in the modeled and real field data experiments, respectively, which are rarely used in this research field. In the numerical experiments, firstly, a layered velocity model is used to verify the advantage of multiples in imaging; secondly, a test is carried out to compare the imaging performance of the conventional and preserved-amplitude one-way wave equation migration methods; finally, a carefully comparison is made between imaging results of primary and multiple waves.

\section{Data and Methods}

In this study, we focused our attention on a seismic line located southwest Chiloé Island (Chile) across the continental slope between $43^{\circ}$ and $44^{\circ} \mathrm{S}$ [39], which is characterized by the subduction of Nazca Plate below the South American continental plate along the Peru-Chile trench at a rate of about $66 \mathrm{~km} \mathrm{Ma}^{-1}[40,41]$. The seismic line, called SO16140 , is located in an area where the last glaciations have modeled the Chilean southern margin [42] and where the tectonic evolution of the fore-arc basin included an inversion from tectonic erosion to accretion [43]. Changes in seismic facies induced by tectonic processes and glaciations should be distinguished from those caused by the presence of gas hydrate and free gas in the sediments, so these aspects are very important to improve the seismic imaging of the hydrate system.

\subsection{Seismic Data Acquisition and Processing}

The seismic profile SO161-40 was acquired by using a 3000 m-long streamer with 132 channels; the inter-trace of the first 24 channels was $12.5 \mathrm{~m}$, while the inter-trace of the remaining channels was $25 \mathrm{~m}$. The shot intervals were equal to $50 \mathrm{~m}$ (see details in [36]).

Data processing was performed by using Seismic Unix package (SU) (44R14, Golden, CO 80401, USA), a free software developed at the Colorado School of Mines [44]. After careful editing to remove noisy traces, a band-pass filter was applied to enhance the quality of reflections and a predictive deconvolution, with an operator length of $120 \mathrm{~ms}$ and a lag of $8 \mathrm{~ms}$, was applied. Then, the one-way GSP as a classical one-way wave equation migration method (method I) is adopted to image seismic data. For comparison, the amplitude-preserved one-way wave equation migration by using matrix decomposition (method II) is applied; the main concepts of this imaging method can be found in the literature (e.g., [30]).

\subsection{Depth Migration Using Primary and Multiple Waves}

Multiple waves are a very common wavefield phenomenon in marine seismic survey. Generally speaking, multiple waves were considered a noise, so it is often attenuated in seismic data processing. After waves are generated by a source and pass thought strata, then they are reflected by strata and propagate forward. Due to the strong impedance contrast at the sea surface, waves are reflected backward and become a down-going wave. When waves propagate between the sea surface and strata, high-order multiple waves in the shot gather can be found, even if its energies attenuate very intensely with the increasing order.

In the modeling, a simple two-layer model was built to test the imaging performance by using primary and multiple waves; the velocity model is shown in Figure 1a. Figure 1b shows a shot gather containing primary and multiple waves, which are calculated by using the finite difference technique. The primary waves are utilized as the source wavefield, and the multiple waves are used as the receiver wavefield to perform depth extrapolation in multiple wave imaging. In order to show the advantage of multiple waves in imaging, the conventional imaging result of primary waves is also included. The imaging results 
of primary and multiple waves are shown in Figure 2. Observing the imaging results, multiple waves enable image the region where the primary waves cannot illuminate. This experiment demonstrates the strength of multiple waves in imaging compared to primary waves and lays a foundation for our further study, especially in imaging the complex structures.

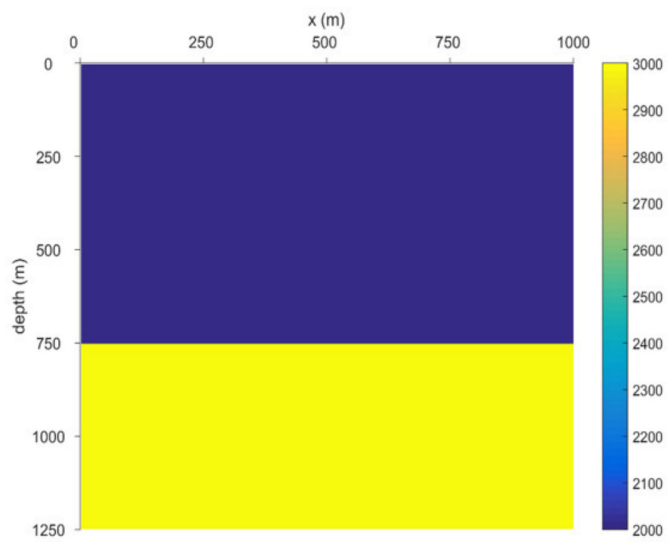

(a)

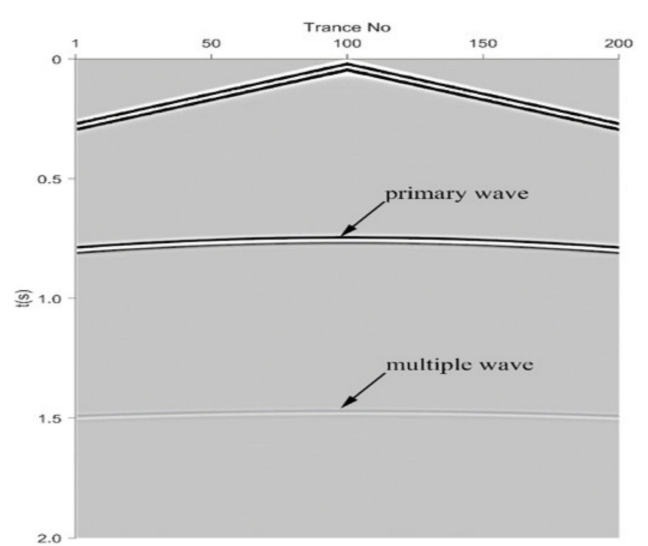

(b)

Figure 1. Velocity model and its simulated wavefields. (a) Layered velocity model; and (b) shot gather containing primary and multiples waves.
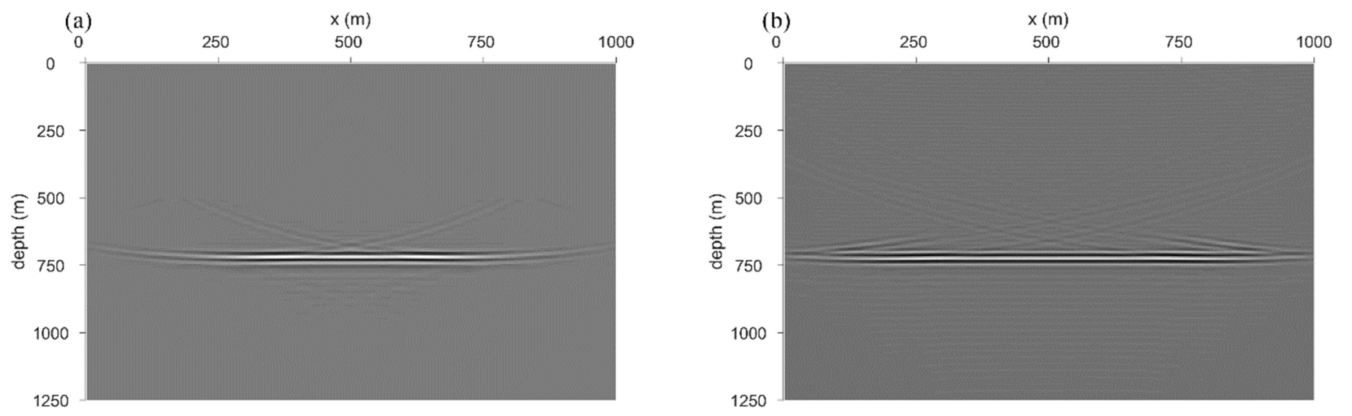

Figure 2. The imaging results obtained by using (a) primary waves; and (b) multiple waves.

\section{Results}

\subsection{Primary Wave Imaging}

The one-way wave equations are split from the full-wave equation, which has kinetical characteristics. However, when the full-wave equation is split, there are high-order items in the original one-way wave equation and the high-order items have close contraction with the amplitudes of wavefield propagations. Previously, researchers have not paid so much attention to the amplitude information; therefore, the high-order items are abandoned. As discussed above, the conventional one-way wave equation methods preserve the phase information of the full wave equation, but kinetical characteristics are lost. With the development of depth migration, amplitude-preserved migration is drawn increasingly interests in the theoretical research and industrial application.

Through the comparison of the imaging results reported in Figure 3, we can observe that the imaging quality is enhanced by using the amplitude-preserved one-way wave equation migration method, especially in the deeper zone, which has been pointed by black dashed box. As for a detailed comparison, we enlarge the local part as shown in Figure 4. Based on the application of amplitude-preserved imaging, the BSR shows a very good continuity, as indicated by arrows in Figure 4. Moreover, we can see that the imaging of some reflecting events and its contact relationships has been improved. 

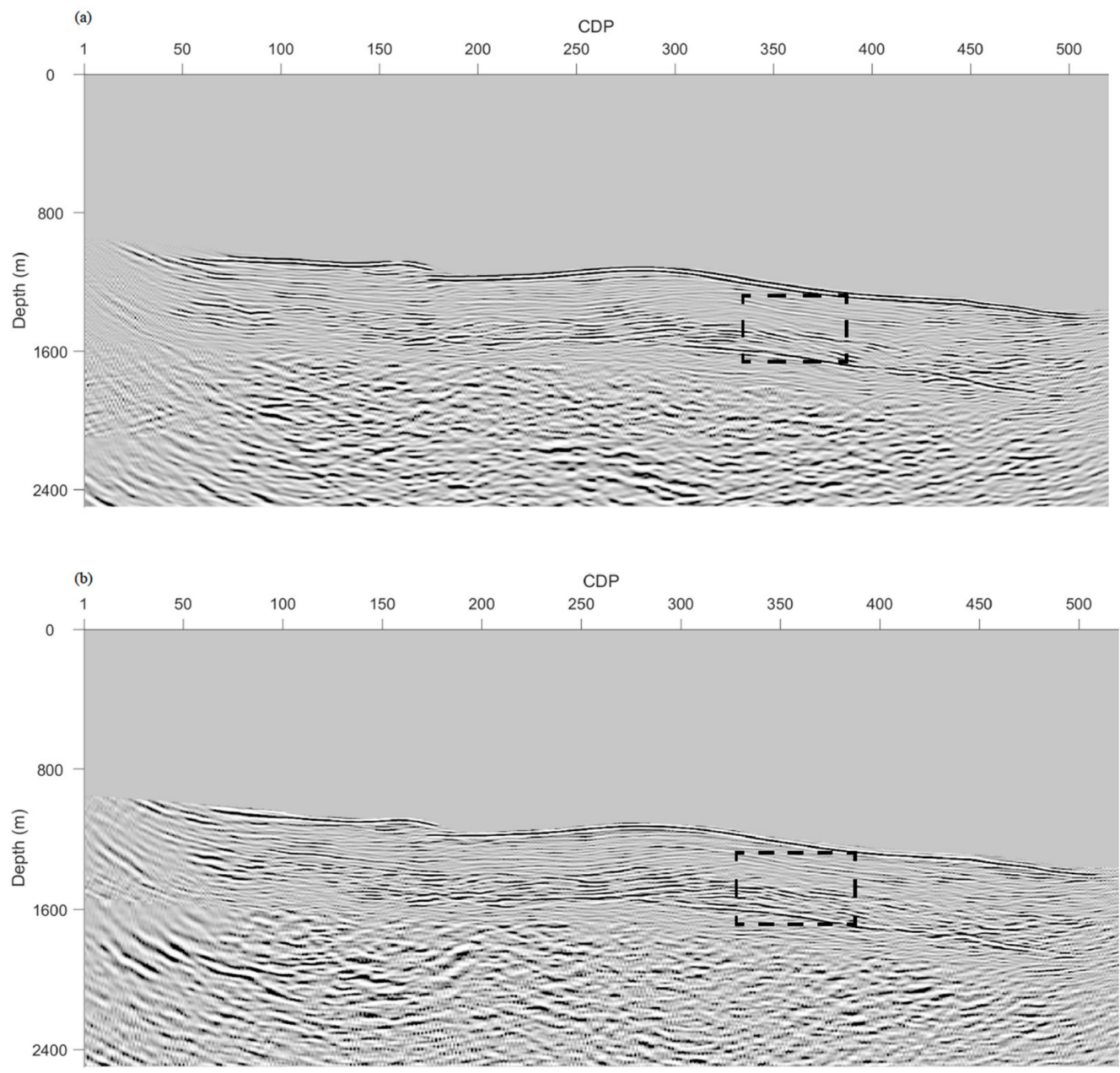

Figure 3. Imaging sections obtained by (a) the conventional one-way wave equation migration; and (b) amplitude-preserved one-way wave equation migration.
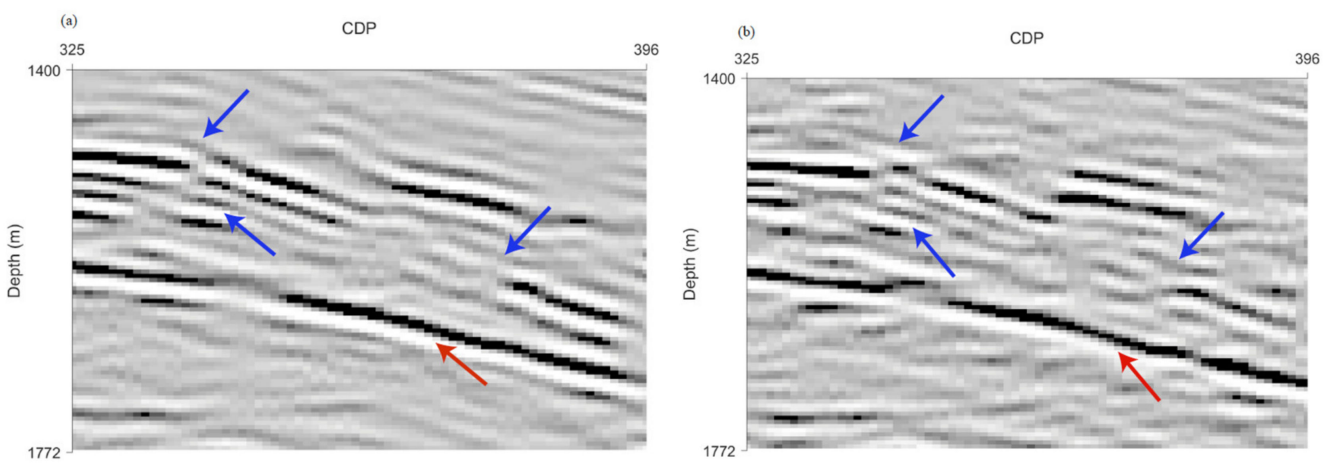

Figure 4. Details of the black dashed box (in Figure 3) using different migration methods: (a) the conventional one-way wave equation migration; and (b) amplitude-preserved one-way wave equation migration. The red arrows indicate the BSR and the blue arrows indicate other reflectors above it.

\subsection{Multiple Wave Imaging}

In the imaging of the gas hydrate system, we attempted to use multiple waves as an imaging supplement for primary waves. The amplitude-preserved one-way wave equation migration method was employed to handle multiple waves and the imaging result is shown in Figure 5. The comparison of the imaging results by using primary and multiple waves shows that the primary waves fail to image the boundaries of the section, while the multiple waves provide a boarder imaging illumination especially for the seafloor 
reflector, as masked by the red dashed box in Figure 5. As the amplitude magnitude of multiples is usually lower than that of the primaries, the reflectors between the subsurface and BSR are imaged weakly. The BSR presents a strong impendence difference because of the gas hydrate and the free gas-bearing strata. Therefore, the multiple waves are used to clearly image the BSR. By comparing the imaging results produced by the primary and the multiple waves, some parts of the BSR are clearly imaged by multiple waves, while they are barely seen in the result of primary waves, as shown in Figure 5. It is worth mentioning that multiple waves are able to image some BSR events, which are very difficult to find in the imaging result of primary waves. This result is beneficial to track the BSR and bring a positive impact to seismic interpretation. Note that multiple imaging improves the illumination in the shallow part.

To better illustrate the results, we zoom in the blue and green dashed boxes of Figure 5 and report the blow-up in Figures 6 and 7, respectively. The feature of the blue area of Figure 5 is that it is located in the shallow part of the section and is closer to the boundary of the seabed, an area which is a good selection to illustrate the advantages of multiple wave imaging. The stable and uninterrupted imaging events are the nature of the blue area of Figure 5, especially for BSR. The blue area is a promising position for GH exploration. Many more imaging details are revealed by using multiple waves. Some events poorly imaged by using primary waves show a better image focusing and enhancement in the result of multiple waves, such as the reflectors in Figures 6 and 7. In addition, the imaging of some waves does not converge so well because of the limited traveling time of primary waves, such as the imaging events in Figures 6 and 7, which vanishes in the result of multiple waves.

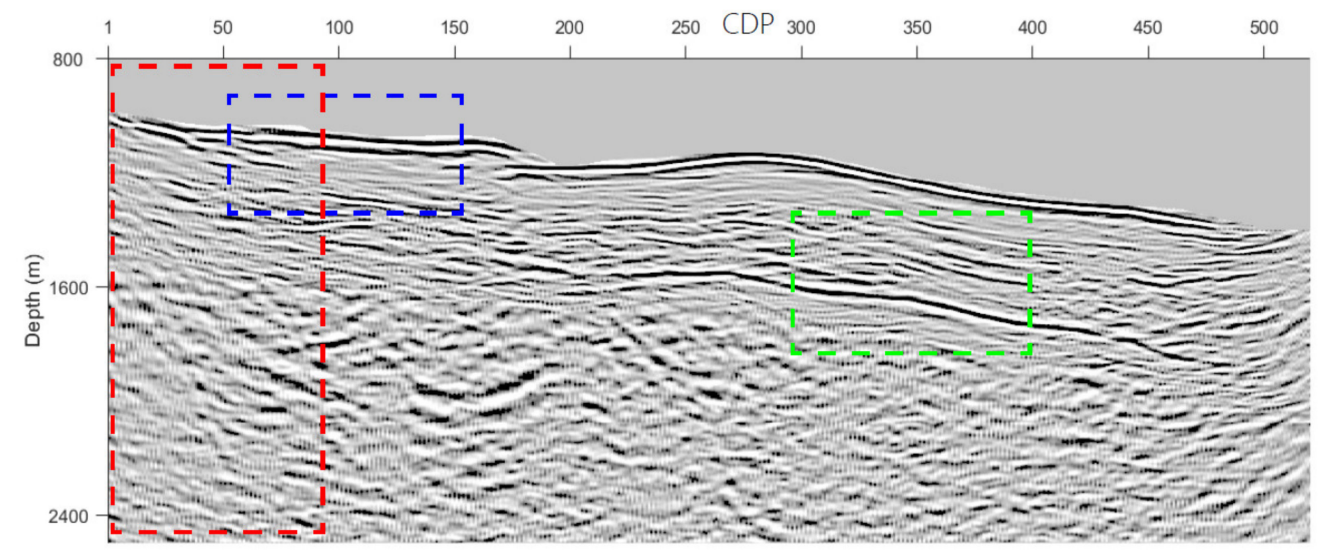

Figure 5. Imaging section calculated by multiple waves. The blue and green dashed boxes indicate the blow-up reported in Figures 6 and 7 respectively. The red dashed box underlines that the boarder effects of the migration are limited.
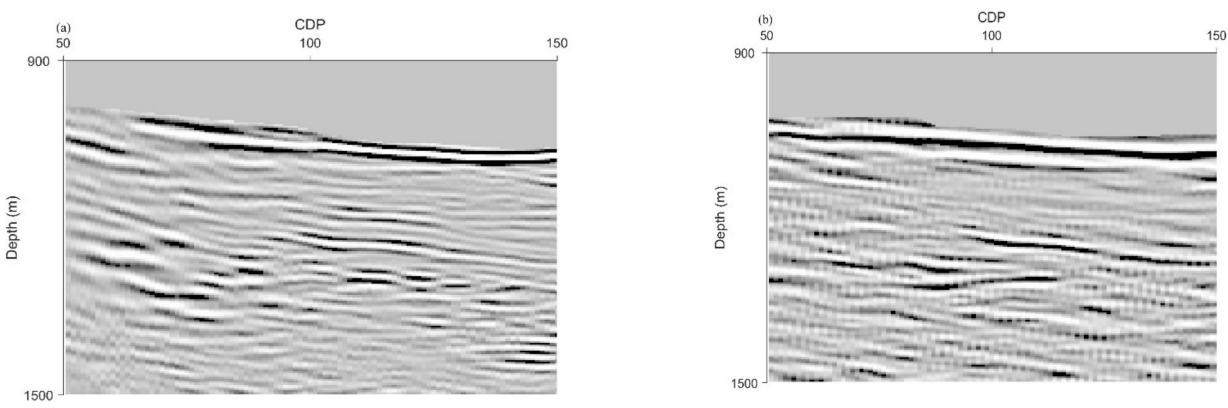

Figure 6. Details of the blue dashed box (in Figure 5) using different kinds of waves: (a) primary wave; and (b) multiple waves. 

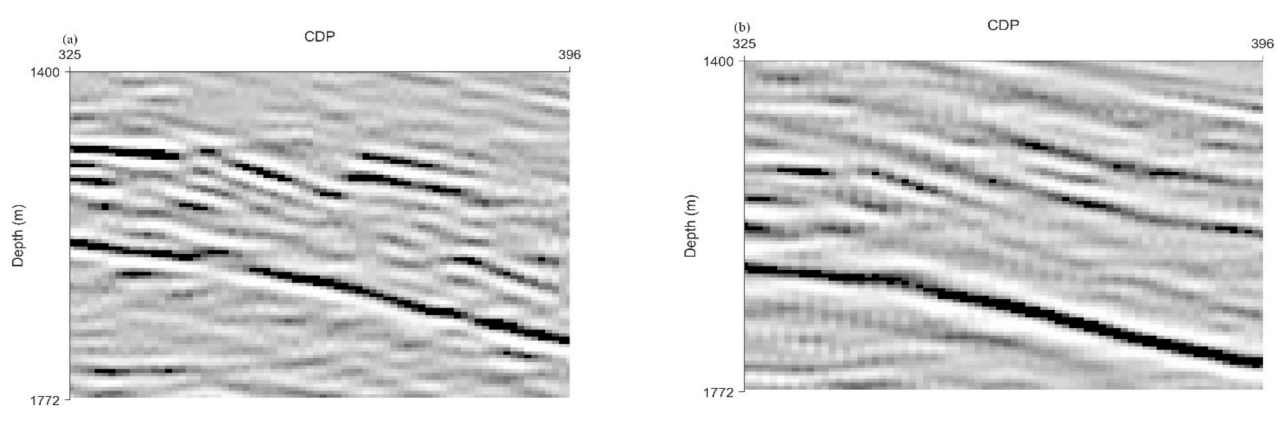

Figure 7. Details of the green dashed box (in Figure 5) using different kinds of waves: (a) primary wave; and (b) multiple waves.

\section{Conclusions}

An imaging section is a basic reference to investigate and identify the distribution of the gas hydrate, such as the identification of the BSR. One-way wave equation migration is the focus of our concern because of its high efficiency. By dealing with the actual marine seismic data, amplitude-preserved one-way wave equation migration is capable of producing more accurate imaging results than the results obtained by using the conventional one-way wave equation. That shows a solid example to support the use of amplitudepreserved one-way wave equation migration method. However, as for primary wave imaging, multiple waves are frequently suppressed. In order to fully use multiple waves, the amplitude-preserved one-way wave equation migration method is used to process them. Compared with the imaging results of primary and multiple waves, we can observe that the multiple waves can image some structures which primary waves fail to image, especially for the shallow part. Moreover, the border effects of the migration are limited, allowing the interpretation at the beginning of the seismic line. In this application, multiple waves are preferred to produce an additional result besides the result of primary waves, which can be useful for the further seismic interpretation of the gas hydrate system.

Author Contributions: Conceptualization and methodology, J.Y.; seismic data processing, S.S.; investigation, writing-original draft preparation, J.Y.; writing—review and editing, U.T., M.G., S.S., and I.V.-C. All authors have read and agreed to the published version of the manuscript.

Funding: This research is supported by National Natural Science Foundation of China (Grant No. 42004103), the Natural Science Basic Research Program of Shaanxi (Grant No. 2021JQ-228) and the Fundamental Research Funds for the Central Universities, CHD, (Grant No. 300102261105).

Institutional Review Board Statement: Not applicable.

Informed Consent Statement: Not applicable.

Data Availability Statement: The data presented in this study are available on request from the corresponding author.

Conflicts of Interest: The authors declare no conflict of interest.

\section{References}

1. Sloan, E.D. Clathrate Hydrates of Natural Gases, 2nd ed.; Marcel Dekker, Inc.: New York, NY, USA, 1998; pp. 1-641, ISBN 0824799372.

2. Kvenvolden, K.A. Gas hydrates-geological perspective and global change. Rev. Geophys. 1993, 31, 173-187. [CrossRef]

3. Tinivella, U.; Accaino, F. Compressional velocity structure and Poisson's ratio in marine sediments with gas hydrate and free gas by inversion of reflected and refracted seismic data (South Shetland Islands, Antarctica). Mar. Geol. 2000, 164, 13-27. [CrossRef]

4. Boswell, R.; Collett, T.S. Current perspectives on gas hydrate resources. Energy Environ. Sci. 2011, 4, 1206-1215. [CrossRef]

5. Johnson, A. Fire In The Ice. In Global Resource Potential of Gas Hydrate-A New Calculation; US Department of Energy, National Energy Technology Laboratory: Pittsburgh, PA, USA, 2011; Volume 1, pp. 1-4. Available online: https://netl.doe.gov/sites/ default/files / publication/MHNews-2011-12.pdf (accessed on 18 June 2021).

6. Collett, T.S.; Boswell, R. Resource and hazard implications of gas hydrates in the Northern Gulf of Mexico: Results of the 2009 Joint Industry Project Leg II Drilling Expedition. Mar. Petrol. Geol. 2012, 34, 1-3. [CrossRef] 
7. Yelisetti, S.; Spence, G.D.; Riedel, M. Role of gas hydrates in slope failure on frontal ridge of northern Cascadia margin. Geophys. J. Int. 2014, 199, 441-458. [CrossRef]

8. Li, A.; Davies, R.J.; Yang, J. Gas trapped below hydrate as a primer for submarine slope failures. Mar. Geol. 2016, 380, 264-271. [CrossRef]

9. Kvenvolden, K.A. Potential effects of gas hydrate on human welfare. Proc. Natl. Acad. Sci. USA 1999, 96, 3420-3426. [CrossRef]

10. Kvenvolden, K.A. A primer on the geological occurrence of gas hydrate. In Gas Hydrates: Relevance to World Margin Stability and Climate Change; Henniet, J.P., Mienert, J., Eds.; Geological Society Special Publication: London, UK, 1998; Volume 137, pp. 9-30. [CrossRef]

11. Kennett, J.P.; Cannariato, K.G.; Hendy, I.L.; Behl, R.J. Methane Hydrates in Quaternary Climate Change: The Clathrate Gun Hypothesis. In Methane Hydrates in Quaternary Climate Change: The Clathrate Gun Hypothesis; American Geophysical Union: Washington, DC, USA, 2003; Volume 54, pp. 1-217, ISBN 9781118665138.

12. Bünz, S.; Mienert, J.; Vanneste, M.; Andreassen, K. Gas hydrates at the Storegga Slide: Constraints from an analysis of multicomponent, wide-angle seismic data. Geophysics 2005, 70, B19-B34. [CrossRef]

13. Mienert, J.; Vanneste, M.; Bünz, S.; Andreassen, K.; Haflidason, H.; Sejrup, H.P. Ocean warming and gas hydrate stability on the mid-Norwegian margin at the Storegga Slide. Mar. Pet. Geol. 2005, 22, 233-244. [CrossRef]

14. Ruppel, C.D. Methane Hydrates and Contemporary Climate Change. Nat. Educ. Knowl. 2011, 3, 29.

15. Ruppel, C.D.; Kessler, J.D. The interaction of climate change and methane hydrates. Rev. Geophys. 2017, 55, 126-168. [CrossRef]

16. Vargas-Cordero, I.; Tinivella, U.; Accaino, F.; Loreto, M.F.; Fanucci, F. Thermal state and concentration of gas hydrate and free gas of Coyhaique Chilean Margin (4430' S). Mar. Pet. Geol. 2010, 27, 1148-1156. [CrossRef]

17. Vargas-Cordero, I.; Tinivella, U.; Accaino, F.; Fanucci, F.; Loreto, M.F.; Lascano, M.E.; Reichert, C. Basal and Frontal Accretion Processes versus BSR Characteristics along the Chilean Margin. J. Geol. Res. 2011, 2011, 1-10. [CrossRef]

18. Marin-Moreno, H.; Giustiniani, M.; Tinivella, U.; Pinero, E. The challenges of quantifying the carbon stored in Arctic marine gas hydrate. Mar. Pet. Geol. 2016, 71, 76-82. [CrossRef]

19. Mulder, W.A.; Plessix, R.E. A comparison between one-way and two-way wave-equation migration. Geophysics 2004, 69, 1491-1504. [CrossRef]

20. Stoffa, P.; Fokkema, J.; de Luna Freire, R.; Kessinger, W. Split-step Fourier migration. Geophysics 1990, 55, 410-421. [CrossRef]

21. Ristow, D.; Rühl, T. Fourier finite-difference migration. Geophysics 1994, 59, 1882-1893. [CrossRef]

22. Le Rousseau, J.H.; de Hoop, M.V. Modeling and imaging with the scalar generalized-screen algorithms in isotropic media. Geophysics 2001, 66, 1551-1568. [CrossRef]

23. Zhang, Y.; Zhang, G.; Bleistein, N. True amplitude wave equation migration arising from true amplitude one-way wave equations. Inverse Probl. 2003, 19, 1113-1138. [CrossRef]

24. Zhang, Y.; Zhang, G.; Bleistein, N. Theory of true-amplitude one-way wave equations and true-amplitude common-shot migration. Geophysics 2005, 70, E1-E10. [CrossRef]

25. Luo, M.; Wu, R.S.; Xie, X.B. True amplitude one-way propagators implemented with localized corrections on beamlets. In Proceedings of the 75th SEG Annual Meeting, Houston, TX, USA, 6-11 November 2005; pp. 1966-1969.

26. Ye, Y.; Li, Z.; Xu, X.; Zhu, X.; Tong, Z. Preserved amplitude migration based on the one-way wave equation in the angle domain. Appl. Geophys. 2009, 6, 50-58. [CrossRef]

27. Vivas, F.A.; Pestana, R.C. True-amplitude one-way wave equation migration in the mixed domain. Geophysics 2010, 75, S199-S209. [CrossRef]

28. Amazonas, D.; Aleixo, R.; Melo, G.; Schleicher, J.; Novais, A.; Costa, J. Including lateral velocity variations in true-amplitude common-shot wave-equation migration. Geophysics 2010, 75, S175-S186. [CrossRef]

29. Liu, D.; Yang, R.; Luo, S.; Wang, P.; Zheng, X.; Song, L. The method of preserved-amplitude seismic migration imaging with stable generalized high order screen. Chinese J. Geophys. 2012, 55, 2402-2411. (In Chinese)

30. You, J.; Wu, R.S.; Liu, X. One-way true-amplitude migration using matrix decomposition. Geophysics 2018, 83, S387-S398. [CrossRef]

31. Dragoset, B.; Verschuur, E.; Moore, I.; Bisley, R. A perspective on 3D surface-related multiple elimination. Geophysics 2010, 75, 75A245-75A261. [CrossRef]

32. Liu, Y.K.; Liu, X.J.; Zhang, Y.B. Migration of seismic multiple reflections. Chinese J. Geophys. 2018, 61, 1025-1037. (In Chinese)

33. Guitton, A. Shot-profile migration of multiple reflections. In Proceedings of the 72th Annual International Meeting, Salt Lake City, UT, USA, 6-11 October 2002; pp. 1296-1299.

34. Shan, G.; Guitton, A. Migration of surface-related multiples: Tests on the Sigsbee2B dataset. In Proceedings of the 74th Annual International Meeting, Denver, CO, USA, 10-14 October 2004; pp. 1285-1288.

35. Zhang, D.; Schuster, G.T. Least-squares reverse time migration of multiples. Geophysics 2014, 79, S11-S21. [CrossRef]

36. Qu, Y.; Li, J.; Guan, Z.; Li, Z. Viscoacoustic reverse time migration of joint primaries and different-order multiples. Geophysics 2020, 85, S71-S87. [CrossRef]

37. Liu, Y.; He, B.; Zheng, Y. Controlled-order multiple waveform inversion. Geophysics 2020, 85, R243-R250. [CrossRef]

38. Nath, A.; Verschuur, D.J. Imaging with surface-related multiples to overcome large acquisition gaps. J. Geophys. Eng. 2020, 17, 742-758. [CrossRef] 
39. De la Cruz Vargas-Cordero, I.; Tinivella, U.; Villar-Muñoz, L.; Giustiniani, M. Gas hydrate and free gas estimation from seismic analysis offshore Chiloé island (Chile). Anden Geol. 2016, 43, 247-263.

40. Angermann, D.; Klotz, J.; Reiberg, C. Space-geodetic estimation of the Nazca-South American Euler vector. Earth Planet. Sci. Lett. 1999, 171, 329-334. [CrossRef]

41. Kendrick, E.; Bevis, M.; Smalley, R., Jr.; Brooks, B.; Vargas, R.B.; Lauría, E.; Fortes, L.P.S. The Nazca-South America Euler vector and its rate of change. J. S. Am. Earth Sci. 2003, 16, 125-131. [CrossRef]

42. Rabassa, J.; Clapperton, C. Quaternary glaciations of the Southern Andes, Quaternary glaciations in the Southern Hemisphere. Quat. Sci. Rev. 1990, 9, 153-174. [CrossRef]

43. Melnick, D.; Echtler, H.P. Inversion of forearc basins in south-central Chile caused by rapid glacial age trench fill. Geology 2006, 34, 709-712. [CrossRef]

44. Cohen, J.K.; Stockwell, J.W. CWP/SU: Seismic Unix Release 4.0: A free Package for Seismic Research and Processing; Center for Wave Phenomena, Colorado School of Mines: Golden, CO, USA, 2008; pp. 1-153. 